\title{
Stationary magnetospheric convection on November 24, 1981. 2. Small-scale structures in the dayside cusp/cleft
}

\author{
Y. I. Galperin ${ }^{1}$, J. M. Bosqued ${ }^{2}$, R. A. Kovrazhkin ${ }^{1}$, A. G. Yahnin ${ }^{3}$ \\ ${ }^{1}$ Space Research Institute of Russian Academy of Sciences, 117810, Moscow, Russia \\ ${ }^{2}$ Centre d'Etude Spatiale des Rayonnements, CNRS/UPS, 9, Avenue du Colonel Roche-31028 Toulouse Cedex, France \\ ${ }^{3}$ Polar Geophysical Institute, Apatity, Murmansk region, 184200, Russia
}

Received: 22 January 1998 / Revised: 19 August 1998 / Accepted: 31 August 1998

\begin{abstract}
A case study of the dayside cusp/cleft region during an interval of stationary magnetospheric convection (SMC) on November, 24, 1981 is presented, based on detailed measurements made by the AUREOL-3 satellite. Layered small-scale field-aligned current sheets, or loops, superimposed to a narrow V-shaped ion dispersion structure, were observed just equatorward from the region of the "cusp proper". The equatorward sheet was accompanied by a very intense and short (less than $1 \mathrm{~s}$ ) ion intensity spike at $100 \mathrm{eV}$. No major differences were noted of the characteristics of the LLBL, or "boundary cusp", and plasma mantle precipitation during this SMC period from those typical of the cusp/cleft region for similar IMF conditions. Simultaneous NOAA-6 and NOAA-7 measurements described in Despirak et al. were used to estimate the average extent of the "cusp proper" (defined by dispersed precipitating ions with the energy flux exceeding $10^{-3} \mathrm{erg} \mathrm{cm}^{-2} \mathrm{~s}^{-1}$ ) during the SMC period, as $\sim 0.73^{\circ}$ ILAT width, $2.6-3.4 \mathrm{~h}$ in MLT, and thus the recently merged magnetic flux, $0.54-0.70 \times 10^{7} \mathrm{~Wb}$. This, together with the average drift velocity across the cusp at the convection throat, $\sim 0.5 \mathrm{~km} \mathrm{~s}^{-1}$, allowed to evaluate the cusp merging contribution to the total cross-polar cap potential difference, $\sim 33.8-43.8 \mathrm{kV}$. It amounts to a quite significant part of the total crosspolar cap potential difference evaluated from other data. A "shutter" scenario is suggested for the ion beam injection/penetration through the stagnant plasma region in the outer cusp to explain the pulsating nature of the particle injections in the low- and medium-altitude cusp region.
\end{abstract}

Key words. Magnetospheric physics (current systems; magnetopause, cusp, and boundary layers; solar windmagnetosphere interactions).

Correspondence to: J. M. Bosqued

\section{Introduction}

Intervals of the stationary magnetospheric convection (SMC) during southward interplanetary magnetic field (IMF) have become an important aspect in magnetospheric studies (see, Sergeev and Lennartson, 1988; Sergeev et al., 1994, 1996; Yahnin et al., 1994). Their existence demonstrated that stationary, or quasi-stationary, conditions can prevail in the nightside magnetosphere over a long time. These observations are in contrast to the concerns on the "pressure balance inconsistency" in a stationary magnetosphere (Erickson and Wolf, 1980) which indicated an instability of the adiabatic lossless convection. Thus it was demonstrated, indirectly, that the large-scale convection is neither adiabatic, nor lossless. Indeed, later stationary models of the nightside magnetosphere were constructed where the magnetic field radial profile within the plasma sheet had a minimum (Hau, 1991; Erickson, 1992), and lateral loss of the particles (mainly in the eveningside direction) was considered. However, the reasons for the magnetospheric stability during long SMC periods with IMF$B_{z}<0$ are still not fully understood. Thus it seems interesting to study in detail the data on the dayside cusp region and on the nightside oval during an SMC period to see if there are any peculiarities with respect to typical established patterns.

On the dayside, the magnetosheath plasma is supposed to be injected to the cusp flux tubes through a region of decreased magnetic field and turbulent stagnant plasma in the outer cusp region of the dayside magnetopause (see, for example, Savin et al., 1997). After merging on the frontside of the magnetosphere in the subsolar and cusp regions (if IMF- $B_{z}<0$ ) or lobe/ cusp/cleft interface region (if IMF- $B_{z}>0$ ), ions injected from the reconnection point (or line) at the same time, but with different field-aligned velocities, will convect poleward (equatorward) with the same $\mathbf{E} \times \mathbf{B}$ convection speed and precipitate in the cusp ionosphere 
at different latitudes: it is the well-known velocity filter effect first modelled by Reiff et al. (1977) and characterized by an observable dispersion, such that energy will decrease (increase) with increasing latitude. Large amount of work was done to interpret these low-altitude velocity dispersed ion profiles and other features in the cusp particle injections (Cowley, 1982; Newell and Meng 1987, 1991, 1992a, b, 1995; Newell et al., 1989, 1991a, b, 1995; Woch and Lundin 1992a, b, 1993; Lockwood and Cowley, 1992; Lockwood and Smith, 1992; Sibeck, 1992, 1993; Onsager et al., 1993; Yamauchi and Lundin, 1994; Sotirelis et al., 1997, and others). Recent studies of the ion velocity dispersion in the cusp from low-altitude satellites (see, for example, Bosqued et al., 1985; Newell and Meng, 1991; Onsager et al., 1993; Sotirelis et al., 1997) and from medium-altitude satellites (Woch and Lundin, 1992a, b) have shown that often the "wing" of the dispersion is observed, either a high-, or a lowlatitude one. It appeared that during the IMF- $B_{z}<0$ periods, accelerated magnetosheath ions are observed mostly at the equatorward side of the cusp, while much colder ions from the plasma mantle are observed poleward form it, with the intensity and average energy decreasing with the latitude within the polar cap. We shall follow the definitions of the dayside precipitation regions established in these papers.

Dayside geophysical measurements at ionospheric altitudes during a particular SMC interval, November 24, 1981, have been already summarized in Despirak et al. (1994) and Yahnin et al. (1994). These data demonstrated that generally the large-scale patterns of convection and particle precipitation on the dayside occur as usual for such IMF- $B_{z}<0$ conditions. The former authors studied the cusp location and its relation to other ionospheric structures using the particle measurements on board the NOAA- 6 and -7 satellites along with the large set of ground-based cusp observations. In agreement with previous studies, they concluded that the cusp is a spot of enhanced low-energy particle precipitation centred near noon. The "cusp region" was shown to be located in the gap of bright discrete auroral arcs pattern and in the longitudinal sector of the dayside convection throat where sporadic auroral rays, but not arcs, were sometimes noted from ground-based observations. It is not clear whether arc-like poleward moving features usually observable in the $630 \mathrm{~nm}$ emission in the cusp (see, Sandholt et al., 1996; Yeoman et al., 1997) were indeed absent, or were indistinguishable by the photographic all-sky camera data.

During this SMC period the cusp region as well as the nightside auroral zone, were crossed by the lowaltitude polar orbiting AUREOL-3 satellite. The AUREOL-3 satellite data will allow first to get detailed information about the plasma close to the cusp region, i.e. in the space-limited region which is presumably the ionospheric footprint of the dayside reconnection site(s). In the present study we present detailed data on the small-scale plasma characteristics during the northern cusp crossing (pass $840 \mathrm{~N}$ ). In a companion work (Galperin and Bosqued, 1998), we shall consider subsequent data from the eveningside and then premidnight oval crossings (same pass, Northern, then Southern Hemisphere). Also some of the reasons are discussed there why substorms did not develop during at least this SMC interval, in contrast to typical prolonged intervals of IMF- $B_{z}<0$.

To our knowledge, the first experimental evidence for the MLT-limited, spot-like cusp geometry of the magnetosheath plasma entry to ionospheric altitudes, as opposed to the elongated cleft geometry popular at that time, was obtained from the AUREOL and AUREOL-2 satellites by Cambou and Galperin (1974), Gladyshev et al. (1974), Sauvaud et al. (1980), see also a review in Cambou and Galperin (1982). Then, the voltage drop due to the reconnection at the cusp (in modern terminology, across the convection throat) deduced from the magnetic flux $\Phi$ through measured cusp "spot" area, divided by the time $\tau$ of a plasma flux tube crossing of this area, was evaluated as $30 \mathrm{kV}$ for relatively quiet conditions (Cambou and Galperin, 1974). Recent results by Newell and Meng (1995) give an average value of $31.4 \mathrm{~V} / \mathrm{km}$ along the merging line projection to ionospheric altitudes (separatrix), which when multiplied by the typical longitudinal extent of the cusp $(1500 \mathrm{~km})$ give a comparable value of the average total potential drop across the cusp convection throat. It is interesting to compare these values deduced from statistical averages of the data from many singular cusp crossings with the essentially $2 \mathrm{D}$ cusp pattern obtained for this SMC period using the compendium of measurements collected by Despirak et al. (1994), and Yahnin et al. (1994) complemented by the AUREOL-3 detailed data.

The final aim of this work is to incorporate the smallscale phenomena observed into the more global perspective already published (see Yahnin et al., 1994), a task hardly feasible during variable conditions and, then, to shed a new light on the small-scale structure of the cusp region processes during the SMC period. This paper will be organized as follows. In Sect. 2 the instrumentation will be briefly introduced; Sect. 3 will be devoted to the presentation of the experimental results on pass $840 \mathrm{~N}$, concentrating the presentation on smallscale phenomena, field-aligned currents, perpendicular heating, low-frequency noise emissions. In Sect. 4 the observed small-scale layering of the field-aligned currents (FACs) found in the LLBL/cusp region will be discussed and, then, some implications on the merging site properties at the magnetopause will be addressed. By using complementary NOAA satellites passes to estimate the cusp extent, the recently merged magnetic flux will be evaluated, as well as the cusp merging contribution to the total cross-polar cap potential difference.

\section{Instrumentation}

The three axis-stabilized AUREOL-3 satellite was launched on September 21, 1981 into a low-altitude polar orbit (perigee: $410 \mathrm{~km}$, apogee: $2000 \mathrm{~km}$, inclination: $82.5^{\circ}$ ) and was in operation for nearly $6 \mathrm{y}$. Description of the scientific payload has been published 
elsewhere (Galperin et al., 1982; see also Annales de Geophysique, special issue, 38, N 5, 1982).

Here the particle data were provided by: (a) the fixedenergy/four channel electrostatic spectrometer RIEP2802 instrument, for two energy levels $(0.1$ and $1.8 \mathrm{keV})$ both for electrons and ions (Galperin et al., 1982a), and (b) the SPECTRO particle instruments (Bosqued et al., 1982) which included a set of multidirectional electrostatic spectrometers (ROT instrument) scanning the $0.03-20 \mathrm{keV}$ energy range in $\sim 1.6 \mathrm{~s}$, and viewing different pitch angle directions, and two energy-mass spectrometers (ION1 and ION2) separating $\mathrm{H}^{+}, \mathrm{He}^{+}$and $\mathrm{O}^{+}$ion species from several eV/e till $14 \mathrm{keV} / \mathrm{e}$, along 2 directions, $\sim 60^{\circ}$ and $\sim 120^{\circ}$ pitch angle.

Magnetic field three-component measurements were made by the TRAC instrument (Berthelier et al., 1982a) which digitized the output of the standard onboard magnetometer designed for attitude determination with a time resolution of $80 \mathrm{~ms}$ or lower, depending on the telemetry mode. In the data processing we used both $D B_{x}$ and $D B_{y}$ components of variations (in the horizontal plane), but show only the dominant $D B_{y}$ component data here. AC electric and magnetic fields were measured by the wave complex ONCH-TBF (Berthelier et al., 1982b), from which only filter-bank data were used on the pass $840 \mathrm{~N}$ through the cusp/cleft region. The ISOPROBE instrument (Béghin et al., 1982) to measure electron density, temperature and their fluctuations, was a double interferometric mutual impedance probe.

Besides the AUREOL-3 data we use here the measurements from the NOAA-6 and NOAA-7 satellites obtained through the World Data Center A. Particle detectors onboard the NOAA satellites consist of three groups of instruments: TED, measuring the electrons and protons within the energy range of 0.3 $17 \mathrm{keV}$, MEPED, measuring particles with energies more than $30 \mathrm{keV}$, and HEPAD, measuring very energetic (hundred of $\mathrm{MeV}$ ) protons and alpha particles (see Hill et al., 1985). The data appropriate for the cusp study were provided by the TED and MEPED instruments. They include the total energy flux obtained by integrating the data from 11 energy channels, the differential particle and energy fluxes in energy ranges of $0.300-0.458,0.770-1.088,1.718-2.349$, and 3.610 $4.870 \mathrm{keV}$, and the energy which corresponds to the maximal energy flux in the measured spectra from TED, and the location of the trapping boundary for energetic electrons from MEPED.

The invariant and other geophysical coordinates were calculated by the CADR program (Galperin et al., 1980). It uses, in its contemporary PC-compatible form CADR-4, the IGRF-90 magnetic field expansion and Tsyganenko-87 magnetospheric model, to calculate, along an orbit and at its conjugate points, the invariant coordinates of the satellite, and other relevant geophysical parameters.

\section{Observations}

During the pass $840 \mathrm{~N}$ on November 24,1981 , in the dayside near noon sector, AUREOL-3 was moving poleward and duskward and, between 0738 and 0741 UT, crossed the successive precipitation regions identified on the particle spectrogram (see Fig. 1) as the dayside extension of the near-Earth plasma sheet (PS), low latitude boundary region (LLBL), or boundary cusp, and plasma mantle (PM), according to the definitions introduced by Newell and Meng (1992b), and Woch and Lundin (1992a, b). This pass occurred during rather stable IMF conditions as monitored by ISEE-3 $\left(204.5 ; 90.0 ;-5.7 R_{E}\right)$ with IMF- $B_{z} \sim-4.95 \mathrm{nT}$; IMF- $B_{y} \sim+1.7 \mathrm{nT} ; \quad N_{s w} \sim 4 \mathrm{~cm}^{-3} ; \quad V_{s w} \sim 320 \mathrm{~km} \mathrm{~s}^{-1}$

\section{AUREOL-3 24 NOV 1981 ORBIT:840_5 MODE:514 SEQ:413}

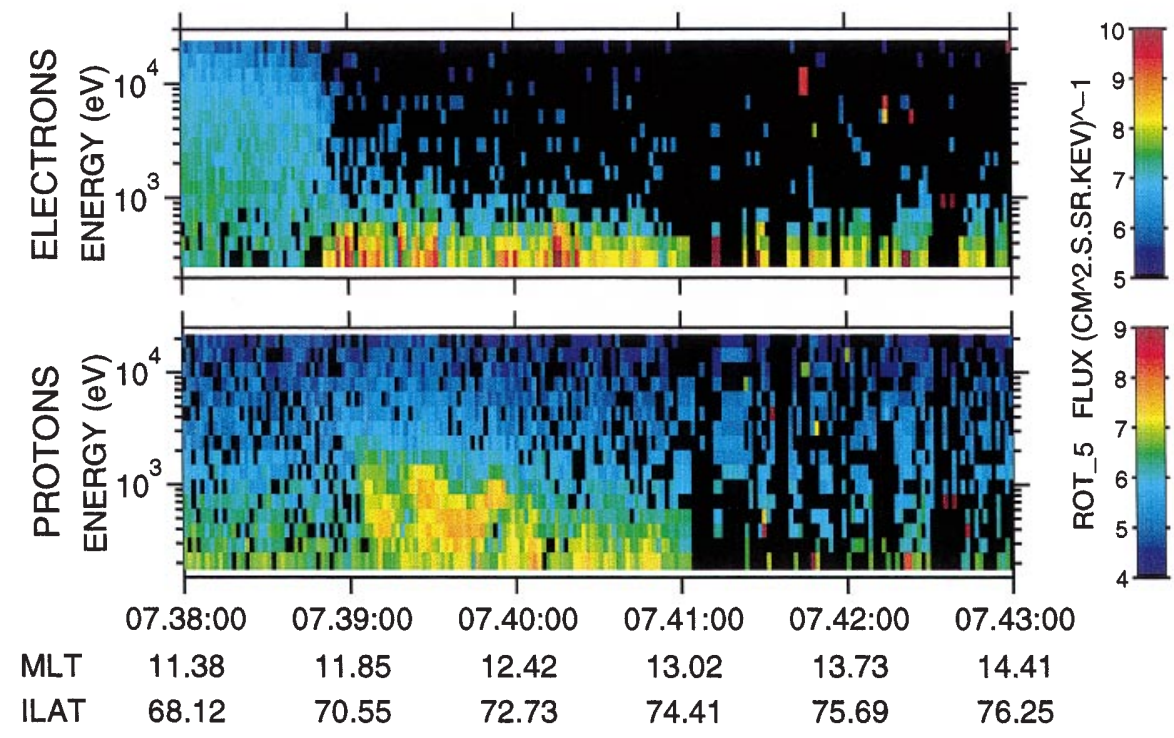

Fig. 1. Colour-coded energy-time spectrograms for $0.2-22 \mathrm{keV}$ electrons and protons (ROBE instrument, sensors ROT_E5/P5) for the AUREOL-3 cusp pass (840 North), plotted as a function of UT, magnetic local time (MLT) and invariant latitude (ILAT) coordinates 
(evaluated for an estimated delay of $\sim 67 \mathrm{~min}$ for the solar wind arrival to the cusp region). The $A E$ index was relatively stable at about $360 \mathrm{nT}$. In agreement with the previous statistical studies (Newell et al., 1989), the cusp region for these IMF conditions was displaced from the average location equatorward to ILAT $\sim 70.5-72.0^{\circ}$, presumably due to the prolonged period with IMF$\mathrm{B}_{z}<0$, and it was extended from prenoon ( $\sim 09.7$ MLT) till postnoon ( 13 MLT), see below.

\subsection{Particle results}

As shown on the electron spectrogram (Fig. 1) provided by the SPECTRO instrument, moving poleward in the noon sector, the AUREOL-3 satellite from 0738:00 to 0738:53 UT (ILAT $=68.17^{\circ}-70.44^{\circ}$ ) crosses, within the trapping boundary, a band of diffuse auroral electron precipitation originating from the dayside extension of the near-Earth plasma sheet. Just at the poleward edge of this diffuse precipitation band, defined at $\sim 0738: 53$ UT as an abrupt decrease of the $\mathrm{keV}$ electrons, near the trapping boundary, several important features appear on the spectrogram as well as on the current, electron/ ion flux, cold plasma and wave profiles (Fig. 2a-e) and will be described. In the following this boundary may be considered as the equatorial boundary of the cusp/cleft region.

3.1.1 First interval: 0738:53-0739:20 UT. First of all, just poleward of the equatorial boundary, between 0.738:57 and 0.739:10 UT (see Fig. 1), the ion spectrogram displays an oblique ion dispersion structure with the energy decreasing towards higher latitudes. If this ion dispersion structure is interpreted as a velocity-filter effect, then the parallel energy of peak flux, $E_{\|}$, can be expressed as a function of latitude ILAT (Reiff et al., 1977):

$E_{\|}=\left(V_{c} \cdot h\right)^{2} \cdot\left(I L A T-I L A T_{\infty}\right)^{-1 / 2}$

where $V_{c}=(\underline{E} \times \underline{B}) / B^{2}$ is the convection drift component along the satellite trajectory (poleward and duskward), $h$ is the distance along the magnetic field line from the injection point to the ionospheric observation point, $I L A T_{\infty}$ is the latitude of the "injection" field line. The parameters of the fit, $\left(V_{c} \cdot h\right)$ and $I L A T_{\infty}$, are $3.396 \mathrm{~km} \mathrm{~s}^{-1} \quad R_{E}$ and $70.23^{\circ}$ ILAT, respectively (Fig. 3). We shall use these parameters to infer the location of the source.

Data provided by the fixed energy detector RIEP2802 allow a detailed and small-scale analysis at the same time interval (Fig. 4). It seems very interesting to notice a prominent $100 \mathrm{eV}$ ion spike detected at 0738:53-54 UT (see Fig. 4b); the most striking feature is that at this time the AUREOL-3 satellite is crossing exactly the latitude $I L A T_{\infty}$ of the injection field line. This spike cannot be detected by the ROT instrument (spectrogram shown in Fig. 1) as this instrument was scanning higher energies at that time. Flux in this narrow spike (1-1.5 s of time) is extremely high, up to $6 \times 10^{6} /\left(\mathrm{cm}^{2} \mathrm{~s} \mathrm{sr} \mathrm{keV}\right)$. This narrowness is not consistent with any significant velocity-latitude dispersion of ions of about $100 \mathrm{~km} / \mathrm{s}$. Moreover, the $100 \mathrm{eV}$-ion spike at $\sim 0738: 53-54$ UT nearly coincides with the boundary of diffuse electron precipitation, or the last closed field line, and with the first high intensity spike of $100 \mathrm{eV}$ electrons (Figs. 2b and 4b). We may remark that such a coincidence of strong and localized ion and electron enhancements is a rather rare feature in our data.

The intense ion spike was centered at the region of an intense $\left(3.05 \mu \mathrm{A} \mathrm{m}^{-2}\right)$ downward current (Fig. 4a) which may be used as the indication of entering the region of a new plasma regime- the cusp.

At the time of the $100 \mathrm{eV}$ ion spike, i.e., around 0738:54 UT, ISOPROBE results (see Fig. 2d) show a rather smooth profile of cold plasma electron density

AUREOL-3 24 NOV 1981840 N CUSP

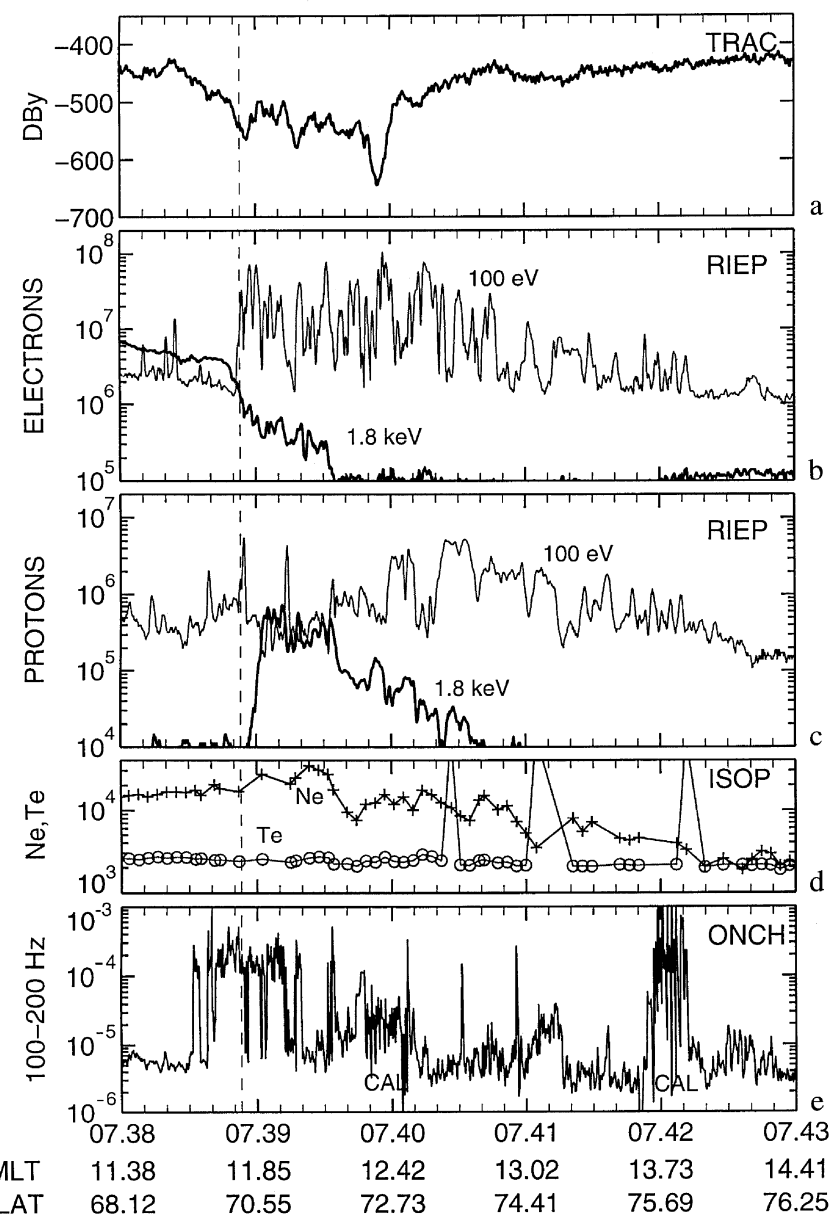

Fig. 2a-e. Overview of AUREOL-3 data for pass 840 North, as a function of time. a The DC magnetic field $D B_{y}$ component (nT) measured by the TRAC instrument; $\mathbf{b}$, $\mathbf{c}$ electron and ion fluxes $\left(\mathrm{cm}^{2} \mathrm{~s} \mathrm{sr} \mathrm{keV}^{-1}\right.$ in 2 separate energy channels, 0.1 and $1.8 \mathrm{keV}$ (RIEP instrument), sampling rate: $320 \mathrm{~ms}$; d cold electron density $N_{e}$ $\left(\mathrm{cm}^{-3}\right)$ and temperature $T_{e}(\mathrm{~K})$ given by the ISOPROBE instrument (identical scale); e electric turbulence (TBF instrument) in the 100$200 \mathrm{~Hz}$ frequency range; an onboard instrument calibration period occurred from 0739:43 to 07.40:04 UT 


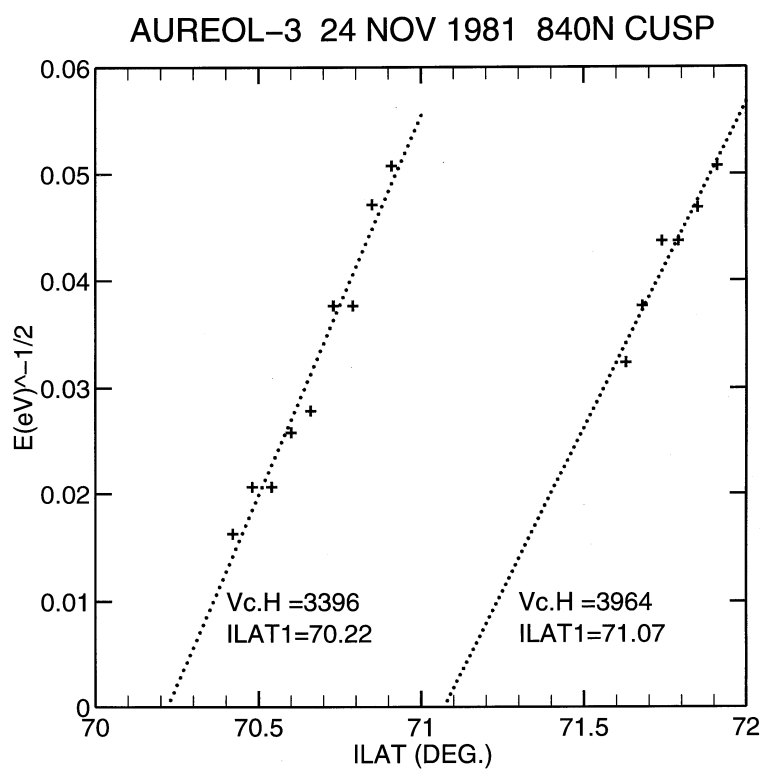

Fig. 3. Inverse root square of the ion energy, $E_{\|}(\mathrm{eV})^{-0.5}$, as a function of the invariant latitude ILAT (degrees), for the two ion energylatitude dispersion events observed on pass 840 . The dotted lines are the linear least square fits to the form (1), with the fit parameters given for each line

\section{AUREOL-3 24 NOV 1981840 N CUSP}
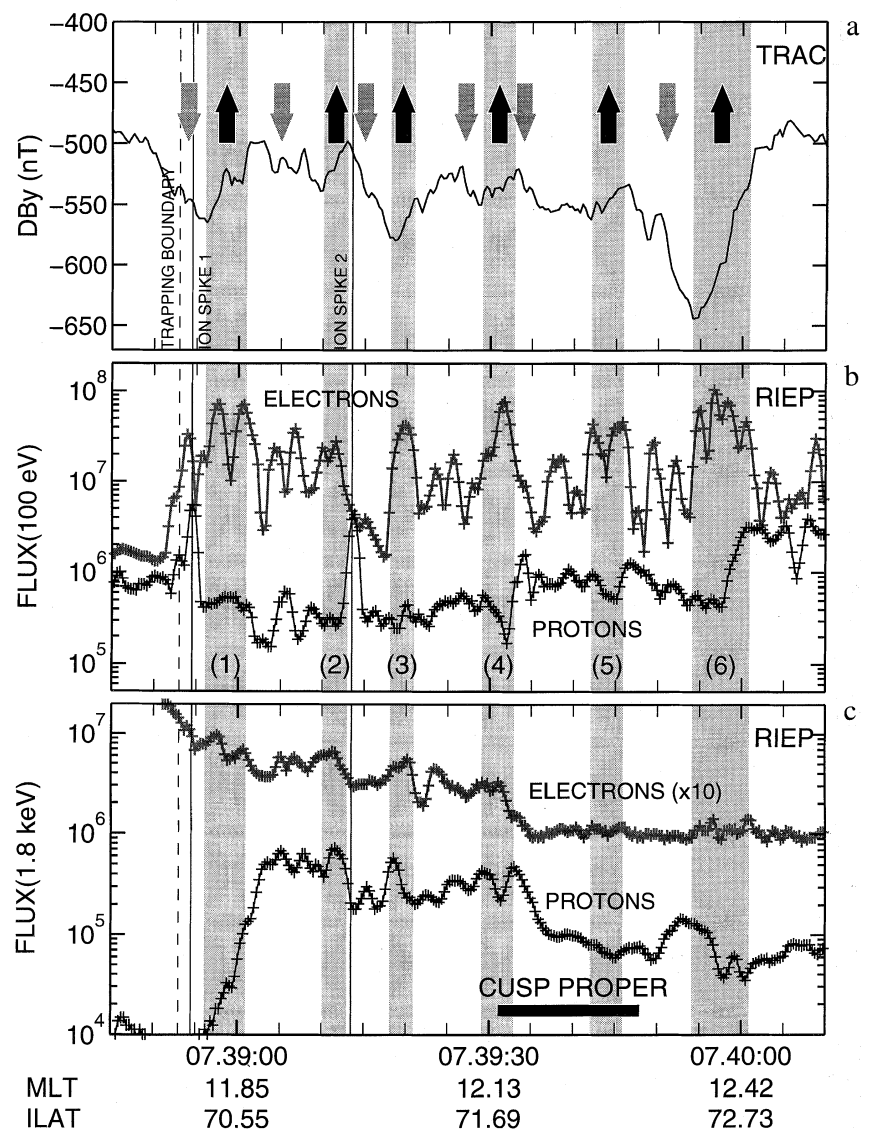

Fig. 4a-c. Expanded view showing 2:30 min of data. Electron flux at $1.8 \mathrm{keV}$ (c) has been multiplied by a factor of 10 . Successive upward field-aligned current sheets are indicated by vertical grey stripes and temperature. The electron density throughout this whole cusp/cleft region was in the range $2-3 \times 10^{3} \mathrm{~cm}^{-3}$, and the absence of sharp gradients probably means that no significant ionospheric plasma flow shears were crossed here. Besides that at such a high electron density no significant electric potential of the satellite with respect to plasma could form during the energetic particle bursts to modify the particle measurements data.

After this unique ion intensity spike at the equatorial boundary of the cusp/cleft region, and up to $\sim 0741$ UT, the $100 \mathrm{eV}$ electron intensities remain high (see spectrogram in Fig. 1) and very structured (Fig. 4b). According to the definitions introduced by Newell and Meng (1992b), and Woch and Lundin (1992a, b), this region can be considered as the ionospheric mapping of the LLBL region. In this region $1.8 \mathrm{keV}$ proton intensity also suddenly increases poleward/eastward from the first spike (Fig. 4c) and reaches $7 \times 10^{5} /\left(\mathrm{cm}^{2} \mathrm{~s} \mathrm{sr} \mathrm{keV)}\right.$ at 0739:05 UT. Later on the $1.8 \mathrm{keV}$ proton intensity remains rather high, and less structured than the $100 \mathrm{eV}$ electrons, throughout all the cusp/cleft region, gradually decreasing by $0741 \mathrm{UT}$, but extending further poleward/ duskward (see later).

3.1.2 Time interval 0739:20-0740:10 UT. Coming back to the large-scale precipitation profiles, a short distance further poleward along the pass, a second proton dispersion structure appears around 0739:29 UT, rather similar to the first one, ending around 0739:37 UT, with lower energies at higher latitudes/eastward longitudes (see Fig. 1). Again, fit of the dispersion curve (Fig. 3) allows determination of the $\left(V_{c} \cdot h\right)$ and $I L A T_{\infty}$ parameters which, for the present case, are respectively $3.964 \mathrm{~km} \mathrm{~s}^{-1} R_{E}$ and $71.07^{\circ}$ ILAT. This "injection" latitude coincides again with the time ( 0739:14 UT) of the second prominent and narrow $100 \mathrm{eV}$ ion intensity spike (Fig. 4b).

Near the polar/eastward edge (lowest energies) of the second ion dispersed structure a new, the third one, but reversed proton dispersion structure is clearly detected between 0739:40 and 0739:56 UT (see Fig. 1), reverse dispersion meaning energy slightly increasing poleward. Together with the second ion dispersed structure it forms a unique doubleside feature resembling a VLF saucer, or a wing. If both sides of this "V-shaped" dispersive feature are interpreted as a result of the velocity-filter effect, an unique reversal of the plasma drift converging to the centre is implied here. However, in between these two dispersion wings, i.e. around 0739:31-0739:48 UT, the intensity of ions of several hundred $\mathrm{eV}$ increases, and the energy flux is mainly carried by ions in the $0.5-1 \mathrm{keV}$ energy. This last interval, 0739:31-0739:48 UT, probably may be considered as the crossing of the "cusp proper" (Newell and Meng, 1992b; Woch and Lundin, 1992a, b), while not all the stated characteristics of this region are present. Nevertheless, this interval is marked "cusp proper" in Fig. 4. 
3.1.3 Time after 0740:10 UT. Finally, poleward of the "cusp proper", there is a general softening of the precipitating protons towards higher latitudes, indicative of a mantle-type precipitation (declining average ion energy and density with increasing latitude) (Fig. 1). Highly structured low energy electrons and ions are intense up to $\sim 0742$ UT (Fig. 2b, c); their flux decreases poleward, and the flux of low-energy $100 \mathrm{eV}$ protons reaches the polar cap level of $\sim 1-2 \times 10^{5} /\left(\mathrm{cm}^{2} \mathrm{~s} \mathrm{sr} \mathrm{keV}\right)$ at 0742:30 UT (ILAT $=76.05$, MLT $=14.01)$. Evidently, these latter, poleward fluxes originate in the plasma mantle rather far tailward of the cusp.

\subsection{Field-aligned currents}

Entry of the AUREOL-3 satellite in the cusp region may be identified by a sharp decrease of high energy electron intensities of the diffuse auroral zone (see Fig. 1, and Fig. $2 \mathrm{~b}$ for $1.8 \mathrm{keV}$ electrons), and by a narrow very intense downward field-aligned current of $3.05 \mu \mathrm{A} \mathrm{m} \mathrm{m}^{-2}$. This boundary coincides with several other important features: the intense $100 \mathrm{eV}$ ion spike described earlier (see Fig. 4b), a start of increase of the $1.8 \mathrm{keV}$ ion intensity, and a series of bipolar magnetic variations (Fig. 4a) perpendicular to the satellite trajectory indicative of double-sheet field-aligned currents (FACs).

On a large-scale, the FAC (smoothed from all the small-scale currents) was downward till about 0739:55 UT, i.e. all along the cusp region, but changed to the upward one in the mantle region till about 0743 UT (ILAT $=76.34^{\circ}$, MLT $=14.36$ ).

On a smaller scale, as shown in detail in Fig. 4c, when the satellite enters the region where the electron intensity at $1.8 \mathrm{keV}$ drops sharply, i.e., from 0738:54 UT, the intensity of 100-300 eV low-energy electrons increases and displays a very irregular, bursty pattern. Small-scale bursts with intensities $\geq 2-3 \times 10^{7} /\left(\mathrm{cm}^{2} \mathrm{~s} \mathrm{sr} \mathrm{keV}\right)$, marked (1), (2), ... (6) in Fig. 4b, are sometimes seen on the fixed-energy $1.8 \mathrm{keV}$ electron flux profile, although less intense. Each of these electron intensity bursts coincides with a similar bipolar variation of the $D B_{y}$ magnetic component which may be interpreted as the crossing of a double field-aligned current sheet; these successive $100 \mathrm{eV}$ electron bursts carry a significant part of the upward-directed current branch with a current density of about $1 \mu \mathrm{A} \mathrm{m}^{-2}$, marked by grey vertical stripes on Fig. 4. Concerning this evaluation it must be noted that the magnetic field horizontal component variations are consistent, and interpreted, as resulting from crossing the extended current sheets. By comparing $100 \mathrm{eV}$ electron and ion flux profiles (see Fig. 4b) some anticorrelation can be noticed between ion and electron intensities for a few electron bursts, for instance bursts (4) and (5). Moreover, some correlation is noticed between the locations of the downward directed current branches in the double current sheets and the intensity of ions of $100 \mathrm{eV}$ and/or $1.8 \mathrm{keV}$ (for instance on the right sides of bursts $2,4,5$ ).

As already said, $100 \mathrm{eV}$ electron and ion bursts persist at least till 0742:30 UT. Both the ROT spec- trogram (Fig. 1) and the RIEP-2802 data profiles displayed in Fig. 2 show that ion and electron energies in these bursts reach 1-2 keV even rather deep in the mantle. However, the magnetometer data do not show any appreciable gradients in this region, thus the respective small-scale FACs stay low and/or very localized.

\subsection{Electrostatic noise}

ELF/VLF waves in a wide range of frequencies are also observed all along this AUREOL-3 pass. The electrostatic noise in the $100-200 \mathrm{~Hz}$ band (see Fig. 2e) is strongly enhanced at $\sim 0738: 30$ UT, i.e., in the poleward part of the intense diffuse electron precipitation where a large-scale downward field-aligned current can be inferred from the $D B_{y}$ variations; similar behavior is observed within the frequency range $10-1000 \mathrm{~Hz}$ (not shown). A correlation between the start time of these broadband noises, downward field-aligned current, and, possibly, of low-energy conics could be significant in understanding of the origin of the "cusp ion fountain".

\subsection{Summary of observations from AUREOL-3}

The large-scale precipitation regions crossed by the AUREOL-3 during the pass $840 \mathrm{~N}$, may be classified using the criteria introduced by Newell and Meng (1987, 1992a, b) and Woch and Lundin (1992a, b) as follows:

a. The region crossed before 0738:53 UT (ILAT $=$ 70.43 ) is undoubtedly the diffuse auroral precipitation within the trapping region.

b. The equatorial boundary of the cusp region was crossed at 0739:53-0739:55 UT and was distinct due to sharp decrease of the high energy electron intensities characteristic for the diffuse auroral zone, by a narrow intense downward field-aligned current, by sharp increase of the $1.8 \mathrm{keV}$ ion intensity, and by an extremely intense spike of $100 \mathrm{eV}$ ions, coincident with the "injection" field line of energy-latitude dispersed ions just poleward from this boundary.

c. Poleward, the "boundary cusp" region, or a LLBL, was crossed from 0738:55 UT to $\sim 0740: 10$ UT. Within this region the interval from 0739:31 to $0739: 48$ UT has many, but not all, the characteristics of the "cusp proper", and may be tentatively classified as such.

d. Both equatorward and poleward from the "cusp proper" so defined, rather intense small-scale double sheets of field-aligned currents are seen. These current sheets, especially in their upward branches, are correlated with intense fluxes of low-energy electrons $(\leq 400 \mathrm{eV})$

e. Then, the mantle-type precipitation is present up to $\sim 0742: 30$ UT (ILAT $=76.0$; MLT $=14.36$ ); no appreciable field-aligned currents are seen poleward from 0742 UT (ILAT $=75.7)$. 


\section{Discussion}

\subsection{Cusp location and extent}

During the November 24, 1981 long SMC period a set of multi-spacecraft data was used to determine, at least approximately, not only the latitudinal width, but also the longitudinal extent of the "cusp proper" region. However, the pattern of auroral features in the cusp/ cleft region, as observed by AUREOL-3 (A3) along this pass, is not fully characteristic of the "cusp proper" according to Woch and Lundin (1992a, b), but has some characteristics of the adjacent region which they called the "boundary cusp", characterized by lower ion fluxes and non-stationary moving precipitation structures. As all these features are observed along pass $840 \mathrm{~N}$, it is thus quite possible that the A3 indeed crossed the rather narrow (or intermittent) "cusp proper", but mostly moved through the LLBL, or the "boundary cusp". A3 probably crossed the "cusp proper" when it passed the central part of the V-shaped ion dispersion form around 0739:31-0739:48 UT. In this region the average electron energy decreases sharply as can be deduced from the comparison of the intensities at $300 \mathrm{eV}$ (ROT) and $100 \mathrm{eV}$ (RIEP-2802), which is consistent with the typical low-temperature magnetosheath electron penetration in the "cusp proper". At that time A3 is located at the geomagnetic noon $(\mathrm{MLT}=12.0)$ at ILAT $\sim 71.7-$ 72.3 .

The NOAA-6 (N6) and NOAA-7 (N7) satellites cusp crossings during this SMC interval were used to define the cusp region locations, i.e. where the total ion energy flux in the $0.3-17 \mathrm{keV}$ energy range exceeded $10^{-3}$ and $10^{-4} \mathrm{erg}\left(\mathrm{cm}^{2} \mathrm{~s}\right)^{-1}$ (Despirak et al., 1994). The criterion used for the cusp determination from the NOAA data was the existence of dispersed low energy proton precipitation poleward of the hard electron precipitation. In Fig. 5 we reproduce, as orbital segments in the ILATMLT frame the cusp region crossings by A3, N6 and N7. As far as its extent in MLT is concerned the pass $217 \mathrm{~N}$ of $\mathrm{N} 7$ does not show fluxes exceeding $10^{-3} \mathrm{erg}\left(\mathrm{cm}^{2} \mathrm{~s}\right)^{-1}$ eastward of 13 MLT. It means that the "cusp proper" was most probably absent at MLT $>13 \mathrm{~h}$. We have no data from the NOAA satellites at MLT $<09 \mathrm{~h}$. But there were no cusp-like precipitations detected by DE-2 at 8.5 MLT from the data on the pass in this region about an hour earlier (D. Winningham, private communication). It provides some evidence that the cusp region was limited to later than $\sim 09 \mathrm{~h} \mathrm{MLT}$.

As described in Despirak et al. (1994), during the SMC period the identification of the "cusp proper" using A3 data would be consistent with the cusp locations given by N6 and N7 satellites by taking their ion energy fluxes higher then $10^{-3} \mathrm{erg}\left(\mathrm{cm}^{2} \mathrm{~s}\right)^{-1}$. Effectively, the A3 cusp location is in good agreement with that defined on pass $12524 \mathrm{n}$ of the N6 satellite, which occurred about $15 \mathrm{~min}$ earlier in UT than the pass $840 \mathrm{~N}$, and was very close to it in the ILAT-MLT frame. This ensures a coherent definition of the cusp boundaries on these satellites despite the difference in the instruments used.

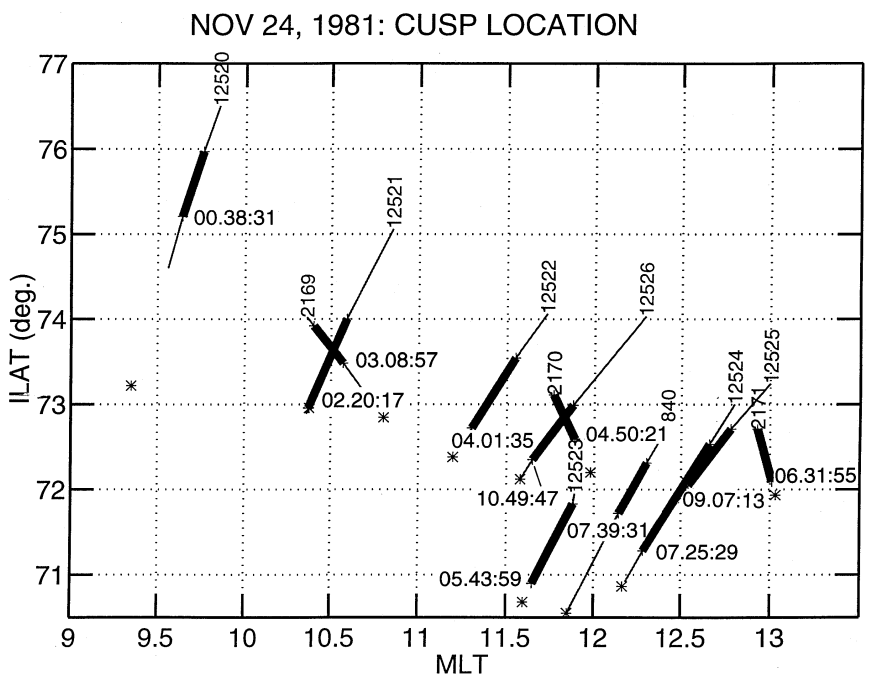

Fig. 5. Cusp crossings by AUREOL-3 (pass 840N), NOAA-6 (passes 12520 to 12526 ) and NOAA-7 (passes 2169 to 2171) on November 1981, plotted in the MLT-ILAT frame. The "cusp proper" crossings, i.e. the regions where the ion energy flux exceeds $10^{-3} \mathrm{erg}\left(\mathrm{cm}^{2} \mathrm{~s}\right)^{-1}$ are shown as heavy lines, while the cusp region with the ion energy flux $>10^{-4} \mathrm{erg}\left(\mathrm{cm}^{2} \mathrm{~s}\right)^{-1}$ as light lines. Note that the invariant coordinates of the NOAA satellites, taken from Despirak et al. (1994), were again computed by the CADR-4 program to make them comparable to the coordinates used for the A3 pass. Trapping boundaries of $>30 \mathrm{keV}$ electrons are indicated by stars

The combination of this described satellite data allows us to construct a 2D pattern of the cusp region. On average for the total of 10 crossings of the cusp region its width in ILAT can be evaluated to be $0.73^{\circ}$ and $1.2^{\circ}$ (or 80.3 , and $137.6 \mathrm{~km}$ at ionospheric altitude), for an ion energy flux exceeding $10^{-3}$ and $10^{-4} \mathrm{erg}$ $\left(\mathrm{cm}^{2} \mathrm{~s}\right)^{-1}$, respectively. Its corresponding maximum extent in MLT is $\sim 3.4$ or $\sim 2.6$ h (i.e. $\sim 1750$ or $\sim 1350 \mathrm{~km}$ ), according to whether the dawn pass 12520 at somewhat higher latitude is included or not. We note a large longitudinal extent of the cusp found, the displacement of its centre to prenoon MLT for IMF$B_{y}>0$, and a skewness to higher latitudes at its late morning part. These particular characteristics are generally consistent with the form of the spatial 2D largescale convection pattern deduced in Despirak et al. (1994). Also, they are qualitatively consistent with the location and skewness of the separatrix expected from the 2D average convection pattern for comparable $K_{P}$ or IMF conditions according to Ruohoniemi and Greenwald (1996) (their Fig. 6 and 8). The voltage drop along the separatrix location expected from these average potential patterns is comparable to that deduced from the above mentioned extent of the "cusp proper" (see later).

\subsection{Narrow ion intensity spikes}

One of the most significant and intriguing signatures in the ion precipitation are the two intense and narrow $100 \mathrm{eV}$ - ion spikes, respectively detected at $\sim 0738: 54$ UT and $\sim 0739: 14$ UT. Their most striking feature is 
their detection on the "injection" magnetic field line of the subsequent ion dispersion structure, the first near the equatorial edge of the "boundary cusp", the second close to the "cusp proper". Each of these spikes was found within an enhanced downward current, in the lower latitude branch of small-scale double current sheets. Their narrowness in time/space (less than $1.5 \mathrm{~s}$ ), and the rather low ion parallel velocity (not more than a couple of hundred $\mathrm{km} / \mathrm{s}$ ), could suggest that these intensity bursts are merely a time-limited, not spacelimited (by the satellite motion).

The exact coincidence (in latitude) of each of these two $100 \mathrm{eV}$ ion spikes with the magnetic field line of initial ion injection, as deduced from the slope of the respective energy-latitude dispersion structures, as well as their quasi-simultaneous detection at ionospheric altitudes with protons of much higher energy $(2-4 \mathrm{keV})$, may suggest that these ion spikes are not $\mathbf{E} \times \mathbf{B}$ dispersed and are probably excited at low altitude by an agent which propagates rather quickly from the reconnection site, presumably located at the outer cusp/ magnetopause. One of the possible candidates could be kinetic Alfvén waves generated in short-time bursts of merging, or in small-scale regions of the magnetic field dissipation/hot plasma releases, located somewhere at the outer cusp/magnetopause. The local velocity of kinetic Alfvén waves is of order of $1000 \mathrm{~km} / \mathrm{s}$, an order of magnitude higher than the velocity of the $100 \mathrm{eV}$ protons. Thus the direct proton acceleration between the walls of a kinetic Alfvén wave does not seem to be really effective for this case, although it could play a role in acceleration of $\sim 100 \mathrm{eV}$ electron spikes which are observed simultaneously. No significant increase of the ELF wave intensity was noted at the time of these spikes.

Another possibility is a low-energy ion acceleration burst, probably at medium or low altitudes above the spacecraft. Although no information can be obtained on the time duration and pitch angle distribution of the ion spikes, such a burst could be accelerated by a fieldaligned electric field. This could be either a quasi-steady downward directed electric potential difference (created, for example, from sustained leakage of high energy electrons through the locally opened flux tubes), or effects of a kinetic Alfvén wave from an impulsive reconnection burst in the outer cusp.

Consider the Alfvén wave option first. This kinetic Alfvén wave location is just the same (in the cusp frame) as that of the $100 \mathrm{eV}$ ion spike observed from A3. As the velocity of the $100 \mathrm{eV}$ ions of the spike is much lower than that of an Alfvén wave, and its perpendicular scale is supposed to be small, their detection at low altitudes will not be simultaneous. Indeed, Maynard et al. (1991) during a storm with $B_{z}<0$ and $B_{y} \gg 0$ have registered from DE-2 a narrow $(\sim 0.5 \mathrm{~s})$ and intense $(\sim \pm 50 \mathrm{mV} /$ $\mathrm{m})$ bipolar electric field spike just at the equatorial border of the cusp region/polar border of the diffuse auroral precipitation, but no intense ion spike was observed from the DE-2 at this time.

With a quasi steady field-aligned potential difference it must persist at least during the flight time of the lowest energy ions in the ion dispersion structure $(100 \mathrm{eV})$, during time $\tau \geq l_{\|} / \mathrm{V}_{\text {IMIN }} \cong 7 R_{E} / 130 \mathrm{~km} / \mathrm{s} \cong 345 \mathrm{~s}$ (see later for the choice of minimal path length $l_{\|}$). This time is shorter, but comparable to the average interval between two injection bursts according to Lockwood et al. (1994). The potential drop above the satellite needs to be near $100 \mathrm{~V}$ which will not affect significantly the velocity-filter results shown in Fig. 3.

In summary, we suggest that in our case of the $100 \mathrm{eV}$ ion spike some acceleration mechanism(s) was probably excited by a kinetic Alfvén wave, resulting in an ion acceleration to $\sim 100 \mathrm{eV}$ somewhere between the spacecraft and, probably, 1-2 $R_{E}$ altitude, or a quasisteady downward directed electric field existed during several minutes at the injection flux tube. A search for similar narrow bursts in the cusp/cleft region is presently continuing on the A3 data, when high time resolution data from the fixed-energy spectrometer RIEP-2802 are available.

\subsection{Local particle acceleration and small-scale current sheets}

Most of the low-altitude features of the cusp/cleft/mantle regions observed during the $\mathrm{A} 3$ pass $840 \mathrm{~N}$ are consistent with the results presented in previous studies (see Bosqued et al., 1991; Newell et al., 1991a; Newell and Meng, 1991, 1992a, b, 1995; Sandholt and Newell, 1992; Woch and Lundin, 1992a, b). The large-scale FACs (downward within the cusp and upward in the postnoon mantle) are consistent with the scheme for $B_{y}>0$ deduced from the VIKING data by Yamauchi et al. (1993).

Interesting, while not unique (see e.g., Berthelier et al., 1989; Bosqued et al., 1991; Moen et al., 1994), are the observations of multiple double FAC sheets and the systematic correlation between upward directed FACs and low-energy $(\sim 100 \mathrm{eV})$ electron intensifications; in a few of these sheets a simultaneous decrease of the $100 \mathrm{eV}$ ion intensity is observed. This last observation is generally indicative of field-aligned potential drops above the satellite, in the upward current branches. The perpendicular duration/scale of these current loops is of the order of 3-10 s or 20-70 km, with an upward current branch of about $2-3 \mathrm{~s}$ or $10-20 \mathrm{~km}$. This is comparable to auroral arc widths often observed in this region (see Sandholt et al., 1996). These results on smallscale FACs, low-energy particle fluxes and plasma turbulence are similar to those obtained by Berthelier et al. (1989) in the prenoon and by Bosqued et al. (1991) in the postnoon sectors of the cusp region. Very similar small-scale particle flux variations in the cusp/cleft region (but without the simultaneous magnetic field/ FAC measurements) were observed by Torbert and Carlson (1980) during a dayside rocket flight experiment. They concluded that local downward acceleration (deceleration) of low-energy electrons (protons) was due to the bursty appearance of field-aligned potential drops at higher altitudes.

Throughout this study we assume, consistently with the magnetic field data, that the observed horizontal 
magnetic field deviations result from the crossing by A3 of extended current sheets on the near-noon part of the cusp equatorial boundary, or at the LLBL projection. In the absence of simultaneous imagery data it seems difficult to distinguish in our data between FAC sheets or more localized FACs, related to rayed auroral forms. However, ground-based optical measurements (all-sky camera in $630.0 \mathrm{~nm}$ ) during a DMSP-F7 cusp crossing (Sandholt and Newell, 1992), during similar IMF conditions $\left(B_{z}<0, B_{y}>0\right)$, show cusp auroral emissions nearly symmetrical around the 11 MLT meridian, and elongated in longitude at its sharp equatorial edge.

Thus, we can conclude that the observed FAC layered structure probably reflects a complicated layered pattern of the FAC generator near the outer cusp/ LLBL/magnetosheath interface. We must notice that these FAC structures begin at the equatorial boundary of the "boundary cusp". According to contemporary views (see Crooker, 1979; Crooker and Burke, 1991; Crooker et al., 1991; Newell and Meng, 1992b; Kennel, 1995), this part of the cusp region is mapped to the LLBL region at the dayside magnetopause and/or outer cusp at its duskside edge. This is the probable reconnection site for interplanetary conditions (IMF$\left.B_{z}<0, B_{y}>0\right)$ prevailing during this SMC period. Thus this layering, or stratification, of the small-scale currents seems characteristic for the LLBL projection around noon, but not for the "cusp proper".

Finally, even though the simplest way to interpret bipolar magnetic variations is in terms of double FAC (infinite) sheets, this interpretation is by no means unique, and other types of current structures may be involved. Indeed, the optical observations of the cusp region show bunches of rays, weak unstable arcs and other small-scale auroral features (Vorobiev et al., 1988; Despirak et al., 1994). From the all-sky camera data at Heiss island collected for November 24, 1981 (Despirak et al., 1994), some localized bursts of auroral rays were noted within the "cusp region". However, from the optical data, auroral arcs on the dayside were observed either only far enough in MLT from the "cusp region", (see also Ohtani et al., 1995), or at the equatorial edge of the "cusp proper" (see Yeoman et al., 1997), i.e. in the "boundary cusp" considered to be within the LLBL projection. The significance of these differences in auroral structures apparently lies in the implied shape of the respective small-scale FAC generators and structures within and outside the "cusp region" projection at the dayside magnetopause.

The small-scale field-aligned currents (whatever their real shape is), closely associated with a highly structured and/or impulsive low-energy electron precipitation in the boundary cusp, or LLBL, evidently reflects the turbulent state of the stagnant magnetosheath plasma at the LLBL, and/or outer cusp, when IMF- $B_{z} \ll 0$. Detailed observations of this stagnant plasma in the outer cusp were recently performed by the INTERBALL-1 (tail probe) and its subsatellite MAGION-4 (Savin et al., 1997; Simunek et al., 1997). Apparently, this is the region where the small-scale current-generating regions (or FTEs, and/or small plasmoids) can be formed. Intensification of these upward currents well could be the cause of the setup of a field-aligned potential drop due to the loss-cone current limitation, resulting in the observed electron acceleration/ion deceleration. Characteristic widths of the sheets/bursts of accelerated electrons/decelerated ions are of order of several kilometers at ionospheric altitudes which translates to several tens to a $1000 \mathrm{~km}$ at the outer cusp.

To conclude, on a larger scale, combination of ground-based magnetometer data collected during the whole SMC interval allowed us to construct the 2D pattern of the equivalent current on the dayside (Despirak et al., 1994). According to this pattern, the pass of A3 occurred at the dusk side of the convection throat where the convection stream lines in the postnoon-toprenoon direction had a significant component perpendicular to the A3 satellite orbit $840 \mathrm{~N}$. The ion dispersion-V structure observed thus may correspond to a scan across different stream lines and then was related also to the lateral extent of the merging region at the magnetopause/cusp.

\subsection{Cusp reconnection and cross-polar cap potential difference}

We assume now that the "cusp proper" is the region of open field lines due to the just recently reconnected magnetic flux. If this indeed is the case, the reconnection rate can be evaluated from its width and lateral extent together with the time needed for a plasma flux tube to cross it. Then the contribution of the cusp reconnection voltage to the total cross-tail potential difference can be evaluated in a way already followed by Cambou and Galperin (1974).

As stated in Sect. 4.1, the average extent of the "cusp proper" in ILAT was $\sim 0.73^{\circ}$ ( or $\sim 80 \mathrm{~km}$ ) for an ion energy flux exceeding $10^{-3} \mathrm{erg}\left(\mathrm{cm}^{2} \mathrm{~s}\right)^{-1}$; the corresponding extent in MLT was evaluated to be between 2.6 and $3.4 \mathrm{~h}$ MLT (or $1350-1750 \mathrm{~km}$ ) at the ionospheric E-region altitudes below the cusp. Now, by multiplying the average magnetic field value at $B \sim 0.5$ $\mathrm{G}$, with the average instantaneous area of the "cusp proper", we estimate the recently merged magnetic flux $\Phi$ as $0.54-0.70 \times 10^{7} \mathrm{~Wb}$. The average plasma drift velocity across the cusp close to the convection throat can be estimated by using the fit parameter $\left(V_{c} . h\right)$ obtained for each of the two dispersion structures observed by the A3 satellite, 3.396 and $3.964 \mathrm{~km} \mathrm{~s}^{-1}$ $R_{E}$, respectively. If we assume that the subsolar reconnection point is located at a radial distance of $10 R_{E}$ (the distance along the field line being $\left.\sim 15 R_{E}\right)$, the minimal convection velocity component $V_{c}$ (along the A3 trajectory) may be estimated to be of the order of $0.36 \mathrm{~km} / \mathrm{s}$, on the average. This value is lower than the evaluation, $0.6 \mathrm{~km} / \mathrm{s}$ (or $E=30 \mathrm{mV} / \mathrm{m}$ ), from the ground measurements presented in Despirak et al. (1994) and than the average value found by Newell and Meng (1995) along the separatrix. It is evident that if the reconnection region is located in the outer cusp as low as $h \sim 7 R_{E}$ as was deduced by Woch and Lundin (1992b) (and not 
near the subsolar point), the convection velocity component $V_{c}$ inferred from $\mathrm{A} 3$ results will be greater, about $0.48 \mathrm{~km} / \mathrm{s}$, but still lower than $0.6 \mathrm{~km} / \mathrm{s}$. Evidently, due to a large angle of the trajectory with the stream lines, these are only lower estimates of the actual convection velocity $V_{T O T}$ along the stream lines. Now, adopting this latter lower bound for the value of $V_{T O T}$ and knowing the time spent by a plasma flux tube in crossing the "cusp proper" (the time $\tau$ of the magnetospheric magnetic flux removal, or opening), this combination allows us to estimate the cusp merging contribution, $U=F / \tau$, to the total cross-polar cap potential difference (Cambou and Galperin, 1974). It appears that $U$ ranges from $\sim 32$ to $\sim 42 \mathrm{kV}$, and thus amounts to a quite significant part of the total cross-polar cap potential difference $U_{\text {tot }}=80-90 \mathrm{kV}$ evaluated from other data by Yahnin et al. (1994) and Sergeev et al. (1996).

Newell and Meng (1995), from low-energy ion cut-off measurements, determined the average merging rate as $31.4 \mathrm{~V} / \mathrm{km}$ along the reconnection line projection at ionospheric altitudes. Multiplying the length of the merging line estimated from the NOAA satellite data as the longitudinal extent of the "cusp proper" (1350$1750 \mathrm{~km}$ ), by the value $31.4 \mathrm{~V} / \mathrm{km}$, we have 42.4 $54.9 \mathrm{kV}$, similar to the earlier estimate. These values are consistent with the typical total potential drop evaluated by Newell and Meng (1995) from the cusp average longitudinal length $(\sim 1500 \mathrm{~km})$ for a somewhat higher average ILAT value. Thus the approach by Newell and Meng (1995) also leads to rather high values of $U$ derived from the low-energy ion data in the "cusp proper".

The extent of the "cusp proper" in ILAT and MLT observed during this SMC period seems rather close to the typical. The "cusp proper" is extended, or widened, in comparison with a "spot" in average extended to $500 \mathrm{~km}$ in longitude as observed by Cambou and Galperin (1974), during quiet conditions. This extension, or widening, during the times of intensive merging is consistent with the predictions by Crooker et al. (1991) and with the experimental results by Maynard et al. (1997) from particle measurements along an extended cusp.

If these two independent evaluations of the $U$ value from the ion precipitation data in the "cusp proper" are indeed reasonable, it can be concluded that the merging at the outer cusp/dayside magnetopause region during the SMC is responsible for a significant fraction of the total potential difference $U_{t o t}$ across the polar cap. If that were true, the pattern of stationary equipotentials would be more concentrated in the convection throat region near the cusp than typical polar cap convection patterns suggest. This situation apparently is not specific for the SMC period in question, as the results by Newell and Meng (1995) suggest that the dayside merging during IMF- $B_{z}<0$ indeed usually plays a significant role in the total potential difference across the polar cap. Just recently a similar conclusion was reached by Baker et al. (1997) from the Goose Bay HF-radar data during a period with IMF- $B_{z}<0$. At the same time, as was shown by Newell and Sibeck (1993), the FTE events contribute only a minor fraction of $U_{t o t}$. So the largescale convection pattern, not its small-scale variations, must determine the potential drop across the convection throat, or along the "cusp proper". Apparently further studies are needed to resolve this inconsistency of the convection patterns expected and observed in the cusp region.

It may be considered (see Lockwood, 1997) that at least a part of the LLBL in the cusp region is located on the open field lines placing the open-closed field boundary equatorward from the "cusp proper". For the observations described above this boundary most probably was crossed at 0738:54 UT where several distinct phenomena including the exceptional $100 \mathrm{eV}$ ion spike occurred (see Sect. 3.1), which indeed was located equatorward from the "cusp proper". Then it may be apparent that the evaluation of the magnetic flux $\Phi$ through the "cusp proper" divided by the convection time $\tau$ across it, as was used by Cambou and Galperin (1974), cannot be used for the estimate of the potential difference $U$ across the convection throat. However it is easy to show that the estimate of $U$ does not depend on the width of the cusp, $L_{\|}$, calculated along the streamlines. It depends only on its longitudinal (cross-throat) extent $L_{\perp}$ and the convection velocity $V_{T O T}$ along the stream lines (or across the separatrix): $U=B L_{\|} L_{\perp} / \tau$, where $\tau=L_{\|} / V_{T O T}$; thus $U=L_{\perp} V_{T O T} B$. It follows that if the mapping of the reconnection line, or band, to the cusp region is narrow and located equatorward from the "cusp proper", the validity of the estimate of $\Phi$ is not affected. The main error in this evaluation is due to the approximate value of the convection velocity in the throat used here. From the lower estimate made and that from the large-scale convection pattern deduced from ground-based data in Despirak et al. (1994) it seems that this error does not affect our conclusions.

It may be suggested, according to Newell et al. (1991a), that a much broader region of the dayside magnetopause must be involved for the penetration of the magnetosheath plasma needed to supply the mantle particles observed in a wide MLT range at ionospheric altitudes on the dayside. If this is indeed the case, then the approach by Cambou and Galperin (1974), used here to evaluate the potential difference from the "cusp" are and the time for this flux removal, incorporates to the merged magnetic flux a number of additional contributions collected from all the spread/patchy/ diffusive particle entries throughout the dayside magnetopause. When combined with the contribution form the LLBL at the flanks on each side, it could be sufficient to cover the total potential drop across the polar cap if it indeed maps to ionospheric altitudes.

However, validity of MHD-based electric field mapping from high magnetospheric altitudes to the ionosphere may be questionable, especially in dynamic situations when the finite Alfvén wave velocity effects may be involved (see Galperin, 1995; Galperin and Feldstein, 1996). On the nightside magnetosphere large discrepancies sometimes were found by Matsuoka et al. (1996) when comparing magnetospheric and ionospheric 
electric fields/plasma flows simultaneously measured by GEOTAIL and EXOS-D. These considerations and observations indicate that some caution is needed when comparing the MHD mapping-based electric field and convection velocity data from widely separated magnetospheric regions.

Thus, analysis of the nature and location of the generator(s) of the cross-tail/cross polar cap potential drop, as well as derivation of the dayside merging characteristics from the low-altitude cusp measurements, may still involve unsolved problems in the SMC conditions also.

\section{5 "Shutter" action in the outer cusp}

One of the problems of the cusp ion injections is the location, extent and time development of the ion source region. While many researchers believe that it is the reconnection line at the front side magnetopause, there is also ample evidence for its location, at least occasional in the outer cusp (see, for example, Woch and Lundin 1992b; Yamauchi and Lundin 1997 and references therein). Their evaluation of distances to the source from ion energy dispersion and electric drift velocity (as in Sect. 4.4 by using A3 data), or from pure time-offlight effects, sometimes give distances in the range $\sim 7$ $10 R_{E}$ which are consistent with the outer cusp, while in another case larger distances are found consistent with the dayside magnetopause. Step-like features in the energy-time spectrograms in the cusp were interpreted as an evidence of short-time (1-2 min) bursts of the reconnection (see, Escoubet et al., 1992; Lockwood, 1994; Yamauchi and Lundin, 1994). Here we would like to indicate a possibility of a "shutter" action of the strong plasma turbulence in the plasma stagnation region of the outer cusp as a potentially possible important modulator of the cusp ion beams presumably originated at the dayside magnetopause or in the outer cusp itself. Observations at the outer cusp by two satellites, INTERBALL-1 and MAGION-4, of the multipoint INTERBALL space project (Galeev et al., 1996) reveal hot highly turbulent stagnant plasma where localized ( $\sim$ hundreds to thousands of $\mathrm{km}$ ) magnetic fluctuations, by an order of magnitude, associated with particle populations moving in different directions, are sometimes seen (Savin et al., 1997). However, the relative amplitude of the magnetic fluctuations rapidly decreases at lower altitudes.

We suggest that the "shutter" action of the turbulent plasma may result as a local "percolation" of the current layers in the stagnant plasma region. The percolation of a series of magnetopause current layers by magnetosheath plasma as a result of plasma turbulence was earlier considered by Galeev et al. (1986). In our scenario for the cusp ion injection, an ion beam emerging from an outside reconnection site (at the dayside magnetopause, or at the outer layers of the stagnant plasma region) sometimes can get through the whole stagnant region and reach low altitudes as a result of such a percolation, but occurring within the stagnant plasma region in the outer cusp. The time scale of such a percolation may be evaluated knowing the average bulk plasma velocities in the stagnant region, tens of kilometers (Savin et al., 1997) and their spatial scales evaluated (hundreds of kilometers), which leads to tens of seconds of time. This is in an order of magnitude agreement with the duration of the "reconnection bursts" deduced, for example, by Lockwood (1994) from low-altitude particle data in the "cusp proper". Such a "shutter" in its various forms is suggested here to be responsible for the observed rapid changes in the source distance, and in its variable time developments, for various ion dispersion forms observed in the cusp by the VIKING satellite (Yamauchi and Lundin, 1994). If such a "shutter" really modulates ion injections in the "cusp proper", no reliable information can be deduced from their characteristics about the merging rate at the subsolar magnetopause or at external regions of the outer cusp. We hope that a careful analysis of the conjugate passes of the INTERBALL satellites and, possibly, also of low-altitude ones, and some luck in space-time development of the cusp injections relative to the satellite's orbits, will make it possible to check the "shutter" idea.

Another, but probably related problem in the cusp data interpretation, is a large latitudinal extent of the outer cusp which seems to be wider than its ionospheric projection as revealed by two-point studies of the cusp region at high altitudes including the outer cusp region (Simunek et al., 1997). We can suggest that the highly turbulent region in the outer cusp extends wider in latitude than the "cusp proper" plasma flux tubes, just as another consequence of the "shutter" concept described above: for each ion injection, the extent of the "percolation" region in much smaller than of the stagnant plasma region itself.

\section{Outer cusp with stagnant plasma}

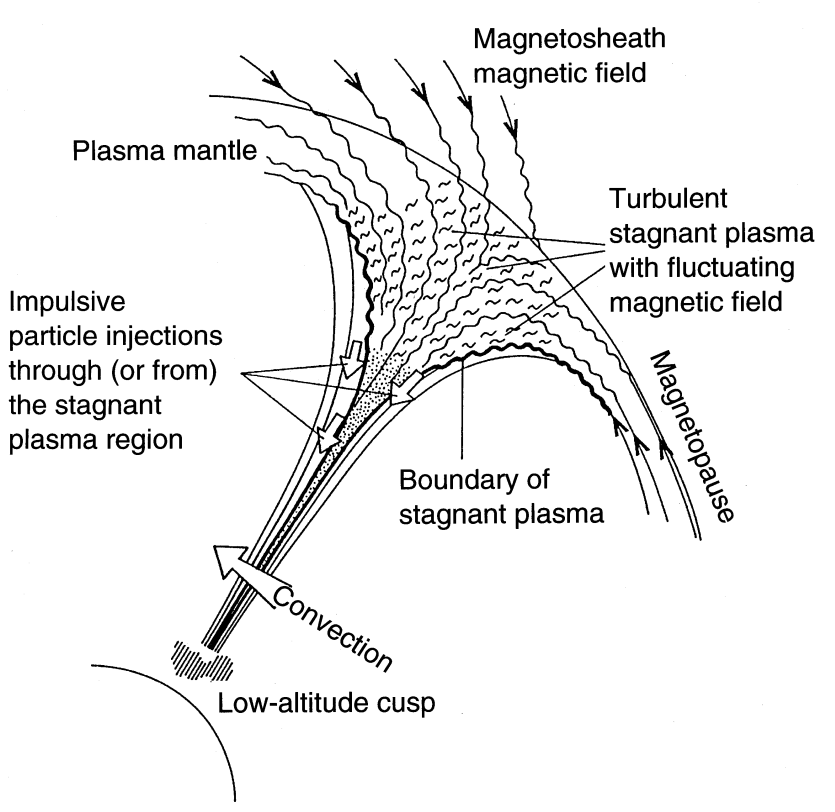

Fig. 6. Sketch of the outer cusp region, including a turbulent stagnant plasma with fluctuating magnetic field (see text for details) 
The "shutter" scenario of pulsed magnetosheath ion penetration to low altitudes, if time-averaged, resembles diffusion through a boundary discussed long ago by Reiff et al. (1977). However if single injections are well separated, the resulting low-altitude pattern will be different, and successive ion dispersed structures should persist and be easily detected as in the A3 pass presented here. A sketch of the gross cusp structure which includes these conjectures, still to be checked against direct measurements, is presented in Fig. 6 .

\section{Summary and conclusions}

During a unique SMC period on November 24, 1981, analysis of the combination of cusp/cleft data provided by an AUREOL-3 single crossing (pass $840 \mathrm{~N}$ ) and multiple crossings by NOAA-6 and N0AA-7 satellites, led to the following conclusions.

1. The general structure of the dayside precipitation region observed in the cusp/cleft region was close to the typical one described by Newell and Meng (1987, 1992b), and Woch and Lundin (1992a, b), for the relevant interplanetary magnetic field and plasma conditions. It includes, at least, the diffuse auroral precipitation region, the "boundary cusp" region, or LLBL mapping to ionosphere, "cusp proper" and mantle-type ion precipitation regions.

2. The latitudinal location, the ILAT-MLT extent of the cusp, and the large-scale pattern of the field-aligned currents in the cusp-mantle regions are consistent with the results of the previous statistical studies.

3. Multiple small-scale FAC loops, or double-sheet currents, are imbedded both in the weak large-scale downward and in the upward current regions in the cusp and mantle regions, respectively. The upward current of each small-scale current loop is mostly carried by lowenergy electrons. The perpendicular duration/scale of these current loops is of order of 3-10 s or $20-70 \mathrm{~km}$, with an upward current branch of about $2-3 \mathrm{~s}$ or 10 $20 \mathrm{~km}$. Such current sheets are comparable in width and FAC intensity to arc-like features often observed in the "boundary cusp" region. These widths can be translated at the outer cusp to dimensions of several tens to a $1000 \mathrm{~km}$. Such scales of the FAC generators at the outer cusp deserve a detailed study from the available and future measurements from high-altitude spacecraft.

4. Very intense short-duration $(\leq 1.5 \mathrm{~s})$ intensity spikes of $100 \mathrm{eV}$ ions are found in the cusp region on the injection field lines of small-scale dispersion structures. Ion acceleration at low or medium altitudes (by kinetic Alfvén waves, or quasi-steady electric potential difference), is suggested for their explanation.

5. The contribution from the cusp reconnection to the total cross-polar cap potential drop $U_{t o t}$ was evaluated using two methods based on the ion precipitation data. It appeared to be quite significant, although the validity of such deductions based on the electric field mapping, stays questionable.

6. A "shutter" scenario is suggested for the ion beam injection/penetration through the stagnant plasma region in the outer cusp to explain the pulsating nature of the particle injections in the low- and mediumaltitude cusp region, and the latitudinal extent of the "cusp proper" which is narrower at low altitudes than at the outer cusp.

Acknowledgements. We thank L. M. Zelenyi, M. Yamauchi and M. Lockwood for stimulating discussions and D. Lagoutte for providing the ISOPROBE data. The NOAA/TED data (PI: D. S. Evans) have been obtained through the WDC A (Rockets and Satellites), thanks to T. Bösinger for assistance in getting the data. DE-2 electric and magnetic field data (PIs: N. Maynard and M. Sugiura) were kindly provided to us by J. King through NSSDC CD-ROM. The work was supported by the INTAS grant 94-1695 and, for YIG and RAK, by the RFBR grant 97-02-16333.

Topical Editor K.-H. Glassmeier thanks P. Escoubet and another referee for their help in evaluating this paper.

\section{References}

Baker, K. B., A. S. Rodger, and G. Lu, HF radar observations of the dayside magnetic merging rate: a geospace environment modeling boundary layer campaign study, J. Geophys. Res., 102, 9603-9617, 1997.

Béghin, C., J. F. Karczewski, B. Poirier, R. Debrie, and N. Massevitch, The ARCAD-3 ISOPROBE experiment for high time resolution thermal plasma measurements, Ann. Geophysicae, 38, N5, 615-629, 1982.

Berthelier, J. J., A. Berthelier, Y. I. Galperin, V. A. Gladyshev, G. Gogly, M. Godefroy, C. Guérin, and J. F. Karczewski, DC magnetic field observations on board the AUREOL-3 satellite: the TRAC experiment, Ann. Geophysicae, 38, 635-642, $1982 \mathrm{a}$.

Berthelier, J. J., F. Lefeuvre, M. M. Mogilevsky, O. A. Molchanov, Y. I. Galperin, J. F. Karczewski, R. Ney, G. Gogly, C. Guérin, M. Levêque, J.-M. Moreau, and F. X. Sené, Measurements of the VLF electric and magnetic components of waves and DC electric field on board the AUREOL-3 spacecraft: the TBF-ONCH experiment, Ann. Geophysicae, 38, N5, 643-667, 1982b.

Berthelier, A., J.-C. Cerisier, J. J. Berthelier, J. M. Bosqued, and R. A. Kovrazhkin, The electrodynamic structure of short scale field aligned currents, and associated turbulence in the cusp and dayside auroral zone, in Electromagnetic Coupling in the Polar Clefts and Caps, eds. P. E. Sandholt and A. Egeland, Kluwer Academic Publishers, Dordrecht, 299-310, 1989.

Bosqued, J. M., H. Barthe, J. Coutelier, J. Crasnier, J. Cuvilo, J. L. Medale, H. Rème, J. A. Sauvaud, and R. A. Kovrazhkin, The low energy electron and ion spectrometers on the AUREOL-3 satellite: the SPECTRO experiment, Ann. Geophysicae, 38, N5, 567-582, 1982.

Bosqued, J. M., J. A. Sauvaud, H. Rème, J. Crasnier, Y. I. Galperin, R. A. Kovrazhkin, and V. A. Gladyshev, Evidence for ion energy dispersion in the polar cusp related to the northward directed IMF, Adv. Space Res., 5, N4, 149-153, 1985.

Bosqued, J. M., A. Berthelier, J. J. Berthelier, and C. P. Escoubet, A case study of the cusp electrodynamics by the AUREOL-3 satellite: Evidence for the FTE signatures?, Geophys. Res. Lett., 18, 1833-1836, 1991.

Cambou, F., and Y. I. Galperin, Résultats d'ensemble obtenus grâce à l'expérience ARCAD à bord du satellite AUREOLE, Ann. Geophysicae, 30, 9-19, 1974.

Cambou, F., and Y. I. Galperin, Main results of the joint FrenchSoviet space project ARCAD-1 and ARCAD-2 for magnetospheric, auroral and ionospheric physics, Ann. Geophysicae, 38, 87-110, 1982.

Cowley, S. W. H., The causes of convection in the Earth's magnetosphere: a review of developments during the IMS, Rev. Geophys., 20, 531, 1982. 
Crooker, N. U., Dayside merging and cusp geometry, J. Geophys. Res., 84, 951-959, 1979.

Crooker, N. U., and W. J. Burke, The cusp/cleft, Rev. Geophys., Suppl., 1017-1027, 1991.

Crooker, N. U., F. R. Toffoletto, and M. S. Gussenhoven, Opening the cusp, J. Geophys. Res., 96, 3497-3503, 1991.

Despirak, I., A. Lubchich, A. G. Yahnin, Y. I. Galperin, S. Vennerstrom, O. Aulamo, and J. D. Craven, Region of cusplike precipitation in day side high latitudes during steady magnetospheric convection, Geomagn. Aeron. (in English), 34, N5, 5-10, 1994.

Erickson, G. M., A quasi-static magnetosphere convection model in two dimensions, J. Geophys. Res., 97, 6505-6522, 1992.

Erickson, G. M., and R. A. Wolf, Is steady state convection possible in the Earth's magnetotail?, Geophys. Res. Lett., 7, 897-900, 1980.

Escoubet, C. P., M. F. Smith, S. F. Fung, P. C. Anderson, R. A. Hoffman, E. M. Basinska, and J. M. Bosqued, Staircase ion signature in the polar cusp: a case study, Geophys. Res. Lett., 19, 1735-1738, 1992.

Galeev, A. A., Y. I. Galperin, and L. M. Zelenyi, INTERBALL project for studies of solar-terrestrial physics, Cosm. Res. (English translation), 34, 313-333, 1996.

Galeev, A. A., M. M. Kuznetsova, and L. M. Zelenyi, Magnetopause stability threshold for patchy reconnection, Space Sci. Rev., 44, 1-41, 1986.

Galperin, Y. I., Magnetospheric tail structure: concepts, problems, and storm-time development of the auroral oval, J. Atoms. Terr. Phys., 57, 1397-1414, 1995.

Galperin, Y. I., and J. M. Bosqued, A Stationary magnetospheric convection on November 24, 1981: 1. A case study of "Pressure gradient/minimum-B" auroral arc generation, Ann. Geophysicae, 17, 358-374, 1998

Galperin, Y. I., and Y. I. Feldstein, Mapping of the precipitation regions to the plasma sheet, J. Geomag. Geoelectr., 48, 857-875, 1996.

Galperin, Y. I., Y. N. Ponomarev, and V. M. Sinitsin, Some algorithms for reference geophysical information along orbits of near-earth's satellites, Preprint IKI, Pr-544, 1-40, 1980.

Galperin, Y. I., M. R. Ainbund, A. D. Boljunova, V. A. Gladyshev, L. S. Gorn, N. V. Jorjio, G. V. Khazanov, A. A. Klimashov, V. G. Kovalenko, R. A. Kovrazhkin, Y. V. Lissakov, B. V. Polenov, Y. N. Ponomarev, A. V. Shifrin, F. K. Shuiskaya, E. B. Usha, J. M. Bosqued, and J. A. Sauvaud, Suprathermal plasma and energetic particle measurements aboard the AUREOL-3 satellite, Ann. Geophysicae, 38, N5, 585-590, 1982a.

Galperin, Y. I., H. Rème, C. Béghin, J. J. Berthelier, J. M. Bosqued, and B. E. Khmyrov, The ARCAD-3 project, Ann. Geophysicae, 32, N5, 543-545, 1982 b.

Gladyshev, V. A., N. V. Jorjio, F. K. Shuiskaya, J. Crasnier and J. A. Sauvaud, Détermination de la position du cornet polaire a l'aide des mesures de particles de basse énergie effectuées à bord du satellite AUREOLE, Ann. Geophysicae, 30, 301-308, 1974.

Hau, L.-N., Effects of steady state adiabatic convection on the configuration of the near-Earth plasma sheet, 2, J. Geophys. Res., 96, 5591-5596, 1991.

Hill, J., D. S. Evans, and H. H. Sauer, TIROS/NOAA satellites space environment monitor archive tape documentation, NOAA Techn. Mem., ERLSEL-71, 1985.

Kennel, C. F., Convection and substorms? in Paradigms of Magnetospheric Phenomenology, Oxford University Press, New York, Oxford, 1995.

Lockwood, M., Ionospheric signatures of pulsed magnetopause reconnection, in Physical Signatures of Magnetospheric Boundary Layer Processes, Eds. J. A. Holtet and A. Egeland, Kluwer Academic Publishers, Dordrecht, pp 229-243, 1994.

Lockwood, M., Relationship of dayside auroral precipitations to the open-closed separatrix and the pattern of convective flow, $J$. Geophys. Res., 102, 17 475-17 487, 1997.

Lockwood, M., and S. W. H. Cowley, Ionospheric convection and the substorm cycle, in SUBSTORMS 1, Ed. C. Mattok, ESP SP-335, Noordwijk, p. 83-88, 1992.
Lockwood, M., and M. F. Smith, The variation of the reconnection rate at the dayside magnetopause and cusp ion precipitation, $J$. Geophys. Res., 97, 14 841-14 847, 1992.

Lockwood, M., T. G. Onsager, C. J. Davis, M. F. Smith, and W. F. Denig, The characteristics of the magnetopause reconnection $\mathrm{X}$ line deduced form low-altitude satellite observations of cusp ions, Geophys. Res. Lett., 21, 2757-2760, 1994.

Matsuoka, A., T. Yamamoto, T. Mukai, and S. Kokubun, Plasma flow in the nightside magnetosphere observed simultaneously by the GEOTAIL and EXOS-D satellites, in Low-Altitude Investigation of Dayside Magnetospheric Boundary Processes, 1, p. 25, 1996.

Maynard, N. C., T. L. Aggson, E. M. Basinska, W. J. Burke, P. Craven, W. K. Peterson, M. Sugiura, and D. R. Weimer, Magnetospheric boundary layer dynamics: DE 1 and DE 2 observations near the magnetopause and the cusp, J. Geophys. Res., 96, 3505-3522, 1991.

Maynard, N. C., E. J. Weber, D. R. Weimer, J. Moen, T. G. Onsager, R. A. Heelis, and A. Egeland, How wide in magnetic local time is the cusp? An event study, J. Geophys. Res., 102, 4765-4776, 1997.

Moen, J., P. E. Sandholt, M. Lockwood, A. Egeland, and K. Fukui, Multiple, discrete arcs on sunward convecting field lines in the 14-15 MLT region, J. Geophys. Res., 99, 6113-6123, 1994.

Newell, P. T., and C.-I. Meng, Energy dependence of the equatorward cutoffs in auroral electron and ion precipitation, J. Geophys. Res., 92, 7519-7530, 1987.

Newell, P. T., and C.-I. Meng, Ion acceleration at the equatorward edge of the cusp: Low altitude observations of patchy merging, Geophys. Res. Lett., 18, 1829-1832, 1991.

Newell, P. T., and C.-I. Meng, Determining the source region of auroral emissions in the prenoon oval using coordinated Polar BEAR UV-imaging and DMSP particle measurements, $J$. Geophys. Res., 97, 12 245-12 252, 1992a.

Newell, P. T., and C.-I. Meng, Mapping the dayside ionosphere to the magnetosphere according to particle precipitation characteristics, Geophys. Res. Lett., 19, 609-612, 1992 b.

Newell, P. T., and C.-I. Meng, Cusp low-energy ion cutoffs: a survey and implications for merging, J. Geophys. Res., 100, 21 943- -21 951, 1995.

Newell, P. T., and D. G. Sibeck, Upper limits on the contribution of flux transfer events to ionospheric convection, Geophys. Res. Lett., 20, 2829-2832, 1993.

Newell, P. T., C.-I. Meng, D. G. Sibeck, and R. P. Lepping, Some low-altitude cusp dependencies on the interplanetary magnetic field, J. Geophys. Res., 94, 8921-8927, 1989.

Newell, P. T., W. J. Burke, C.-I. Meng, E. R. Sanchez, and M. E. Greenspan, Identification and observations of the plasma mantle at low altitude, J. Geophys. Res., 96, 35-45, 1991a.

Newell, P. T., S. Wing, C.-I. Meng, and S. Sigillito, The auroral oval position, structure and intensity of precipitation from 1984 onwards: an automated online data base, J. Geophys. Res., 96, 5877-5882, 1991b.

Ohtani, S., T. A. Potemra, P. T. Newell, L. J. Zanetti, T. Iijima, M. Watanabe, M. Yamauchi, R. D. Elphinstone, O. de la Beaujardiere, and L. G. Blomberg, Simultaneous prenoon and postnoon observations of three field-aligned current systems from VIKING and DMSP-F7, J. Geophys. Res., 100, 119-136, 1995.

Onsager, T. G., C. A. Kletzing, J. B. Austin, and H. MacKiernan, Model of magnetosheath plasma in the magnetosphere: cusp and mantle particles at low-altitudes, Geophys. Res. Lett., 20, 479-482, 1993.

Reiff, P. H., T. W. Hill, and J. L. Burch, Solar-wind plasma injection at the dayside magnetospheric cusp, J. Geophys. Res., 82, 479-491, 1977.

Ruohoniemi, J. M., and R. A. Greenwald, Statistical patterns of high-latitude convection obtained from Goose Bay HF radar observations, J. Geophys. Res., 101, 21 743-21 763, 1996.

Sandholt, P. E., and P. T. Newell, Ground and satellite observations of an auroral event at the cusp/cleft equatorward boundary, J. Geophys. Res., 97, 8685-8691, 1992. 
Sandholt, P. E., C. J. Farrugia, P. Stauning, S. W. H. Cowley, and T. Hansen, Cusp/cleft auroral forms and activities in relation to ionospheric convection; responses to specific changes in solar wind and interplanetary magnetic field conditions, J. Geophys. Res., 101, 5003-5020, 1996.

Sauvaud, J. A., Y. I. Galperin, V. A. Gladyshev, A. K. Kuzmin, T. M. Muliarchik, and J. Crasnier, Spatial inhomogeneity of magnetosheath proton precipitation along the dayside cusp from the ARCAD experiment, J. Geophys. Res., 85, 5105-5112, 1980.

Savin, S. P. et al., Interball tail probe measurements in outer cusp and boundary layers, in Encounter between global observations and models in the ISTP era, Eds. D. Gallagher, J. Horwitz, and T. E. Moore, AGU Monograph Series, Washington D.C., (submitted), 1997.

Sergeev, V. A., and W. Lennartson, Plasma sheet at X $\sim-20 \mathrm{Re}$ during steady magnetospheric convection, Planet. Space Sci., 36, 353-370, 1988.

Sergeev, V. A., R. J. Pellinen, and T. I. Pulkkinen, Steady magnetospheric convection: a review of recent results, Space Sci. Rev., 75, 551-604, 1996.

Sergeev, V. A., T. I. Pulkkinen, R. J. Pellinen, and N. A. Tsyganenko, Hybrid state of the tail magnetic configuration during steady convection events, J. Geophys. Res., 99, 23 571-23 582, 1994.

Sibeck, D. G., Transient events in the outer magnetosphere: boundary waves of Flux Transfer Events?, J. Geophys. Res., 97, 4009-4026, 1992.

Sibeck, D. G., Transient magnetic field signatures at high latitudes, J. Geophys. Res., 98, 243-256, 1993.

Simunek, J., J. Merka, J. Safrankova, Z. Nemecek, A. Skalsky, and N. Rybeva, The high-latitude cusp (Abstr), Ann. Geophysicae, 15, Suppl. III, C681, 1997.

Sotirelis, T., P. T. Newell, and C.-I. Meng, Polar rain as a diagnostic of recent rapid dayside merging, J. Geophys. Res., 102, 7151-7157, 1997.

Torbert, R. B., and C. W. Carlson, Evidence for parallel electric field particle acceleration in dayside auroral oval, J. Geophys. Res., 85, 2909-2914, 1980.
Vorobiev, V. G., V. L. Zverev, and S. V. Leontiev, Structure of auroral luminosity in the noon sector, Geomagn. Aeron. (in Russian), 28, 256-261, 1988.

Woch, J., and R. Lundin, Magnetosheath plasma precipitation in the polar cusp and its control by the interplanetary magnetic field, J. Geophys. Res., 97, 1421-1430, 1992a.

Woch, J., and R. Lundin, Signatures of transient boundary layer processes observed with VIKING, J. Geophys. Res., 97, 14311447, $1992 b$.

Woch, J., and R. Lundin, The low-latitude boundary layer at midaltitudes: identification based on VIKING hot plasma data, Geophys. Res. Lett., 20, 979-982, 1993.

Yahnin, A. G., M. V. Malkov, V. A. Sergeev, R. J. Pellinen, O. Aulamo, S. Vennerstrom, E. Friis-Christensen, K. Lassen, C. Danielsen, J. D. Craven, C. Deehr, and L. A. Frank, Features of steady magnetospheric convection, J. Geophys. Res., 99, 40394051, 1994.

Yamauchi, M., and R. Lundin, A narrow region of electron beams at the poleward edge of the cusp, J. Geophys. Res., 98, 7585$7591,1993$.

Yamauchi, M., and R. Lundin, The wave-assisted cusp model: comparison to low-altitude observations, Phys. Chem. Earth, 22(7-8), 729-734, 1997.

Yamauchi, M., and R. Lundin, Classification of large-scale and mesoscale ion dispersion patterns observed by VIKING over the cusp-mantle region, in Physical Signatures of Magnetospheric Boundary Layer Processes, Eds. Holter, J. and A. Egeland, Kluwer Academic Publishing, Dordrecht, Holland, pp 99-109, 1994.

Yamauchi, M., R. Lundin, and J. Woch, The interplanetary magnetic field by effects on large-scale field-aligned currents near local noon: contributions from cusp part and non-cusp part, J. Geophys. Res., 98, 5761-5767, 1993.

Yeoman, T. K., M. Lester, S. W. H. Cowley, and S. E. Milan, Simultaneous observations of the cusp in optical, DMSP and HF radar data, Geophys. Res. Lett., 24, 2251-2254, 1997. 